Military Technical College Kobry El-Kobbah, Cairo, Egypt

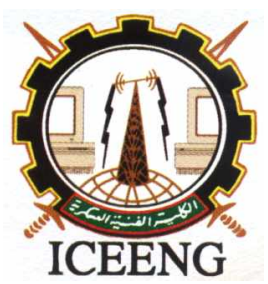

\author{
$6^{\text {th }}$ International Conference \\ on Electrical Engineering \\ ICEENG 2008
}

\title{
A matrix converter controlled with the optimum amplitude-direct transfer function approach
}

\author{
By \\ Hulusi KARACA * \\ Ramazan AKKAYA *
}

\section{Abstract:}

In this paper, a three-phase-in three-phase-out matrix converter (MC) is modeled and its working principles are analyzed. A simple model of the power circuit is proposed, which has a small filter at input side of converter to remove distortion of the input current around the switching frequency. The control signals of the power switches are produced using the optimum amplitude-direct transfer function approach (DTFA). The modulation strategy of the converter is explained mathematically in a clear form. The simulation results obtained from the model at various operating conditions are presented. These results prove effectiveness of the proposed matrix converter model with a unity input power factor. Consequently, the designed PSIM model can be confidently used in the construction stage of the matrix converter.

\section{Keywords:}

Matrix converters, ac-ac converters and DTFA

* Department of Electrical\&Electronics, Selcuk University, Konya, TURKEY. 


\section{Introduction:}

One of the most interesting members of the power converter family is the matrix converters providing directly ac-ac power conversion. Matrix converters firstly introduced in 1976 started to improve after Venturini and Alesina proposed a generalized high-frequency switching strategy in 1980 [1,2]. There are a lot of advantages of the MC's according to traditional converters: It can produce the output voltages with the desirable amplitude and frequency. Energy regeneration can be done to the mains. Sinusoidal input currents can be drawn from mains and input displacement factor can be controlled. Furthermore, the matrix converter allows a compact design due to the lack of dc-link capacitors for energy storage [3]. These attractive properties have prompted researchers to study about the MC.

The physical realization of the MC is not straightforward, and the number of the devices in the power circuit is high compared with that of the inverter. Therefore, it is crucial to obtain an effective model and to test it before constructing a working prototype of the MC [4]. However, popular circuit-oriented simulation software packages such as PSPICE and PSIM haven't the simulation of an MC as a standard block in their libraries [5]. To compensate this necessity, an effective model of the MC was developed by using PSIM package program, shown in figure 1.

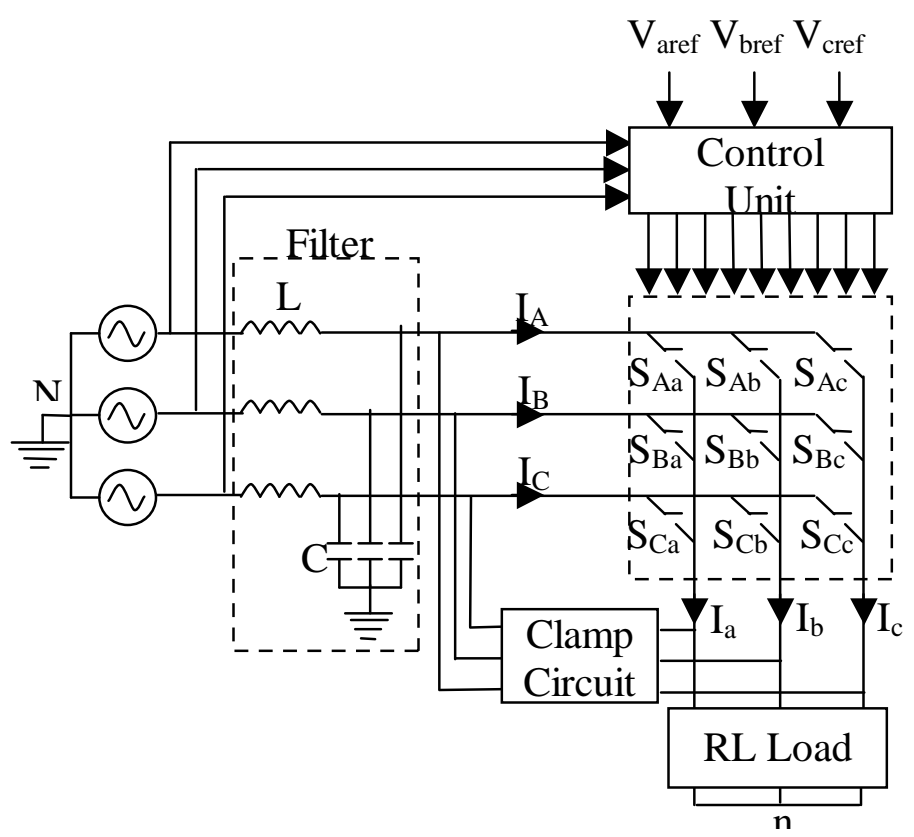

Figure (1): Matrix converter with clamp circuit and input filter 
In this study, the basic concepts of matrix converters are explained and the mathematical model of matrix converters is briefly given. The control signals applied to bidirectional power semiconductors are produced using optimum amplitude-direct transfer function approach and a maximum voltage transfer ratio $(\% 86,6)$ was obtained. An input filter is used at input side of converter. It smoothes distortion of the input current around the switching frequency and avoids the generation of overvoltage produced by the fast commutation of currents due to the presence of the short-circuit reactance of any real power supply. Also, a clamp circuit is added to prevent damaging of the power switches due to over-voltages or over-currents. The working principles of MC producing the output voltages at various amplitude and frequency are analyzed.

\section{Mathematical model of optimum amplitude-DTFA}

Modulation is the procedure used to generate the appropriate firing pulses to each of the nine bidirectional switches. The objective of the modulation is to generate variable frequency and variable amplitude sinusoidal output voltages from the fixed frequency and fixed amplitude input voltages.

If it is defined as $t_{K j}$ : the time during which switch $S_{K j}$ is on, $T_{s}$ : the sampling interval, $\mathrm{m}_{\mathrm{Kj}}(\mathrm{t})=\mathrm{t}_{\mathrm{Kj}} / \mathrm{T}_{\mathrm{s}}$ : duty cycle of switch $\mathrm{S}_{\mathrm{Kj}}$, modulation matrix is given in Eq. (1).

$$
M(t)=\left[\begin{array}{ccc}
\mathrm{m}_{\mathrm{Aa}}(\mathrm{t}) & \mathrm{m}_{\mathrm{Ba}}(\mathrm{t}) & \mathrm{m}_{\mathrm{Ca}}(\mathrm{t}) \\
\mathrm{m}_{\mathrm{Ab}}(\mathrm{t}) & \mathrm{m}_{\mathrm{Bb}}(\mathrm{t}) & \mathrm{m}_{\mathrm{Cb}}(\mathrm{t}) \\
\mathrm{m}_{\mathrm{Ac}}(\mathrm{t}) & \mathrm{m}_{\mathrm{Bc}}(\mathrm{t}) & \mathrm{m}_{\mathrm{Cc}}(\mathrm{t})
\end{array}\right]
$$

In accordance with this, each output phase voltages can be expressed by Eq. (2).

$\left[\mathrm{v}_{\mathrm{o}}(\mathrm{t})\right]=[\mathrm{M}(\mathrm{t})]\left[\mathrm{v}_{\mathrm{i}}(\mathrm{t})\right]$

In the same way, the input currents are also shown by expression in Eq. (3).

$\left[\mathrm{i}_{\mathrm{i}}(\mathrm{t})\right]=[\mathrm{M}(\mathrm{t})]^{\mathrm{T}}\left[\mathrm{i}_{\mathrm{o}}(\mathrm{t})\right]$

where, $[\mathrm{M}(\mathrm{t})]^{\mathrm{T}}$ is the transpose matrix of $[\mathrm{M}(\mathrm{t})]$. Because the $\mathrm{MC}$ is fed by a voltage source, the input terminals should never be short-circuited and, an output phase must never be open-circuited, owing to the fact that the absence of a path for the inductive load current leads to the over-voltages. These constraints discussed can be expressed by Eq. (4). 
$\sum_{\mathrm{K}=\mathrm{A}, \mathrm{B}, \mathrm{C}} \mathrm{m}_{\mathrm{Ka}}(\mathrm{t})=\sum_{\mathrm{K}=\mathrm{A}, \mathrm{B}, \mathrm{C}} \mathrm{m}_{\mathrm{Kb}}(\mathrm{t})=\sum_{\mathrm{K}=\mathrm{A}, \mathrm{B}, \mathrm{C}} \mathrm{m}_{\mathrm{Kc}}(\mathrm{t})=1$

If the input voltages of the MC are

$\left[v_{i}(t)\right]=V_{i m}\left[\begin{array}{l}\cos \left(\omega_{i} t\right) \\ \cos \left(\omega_{i} t+2 \pi / 3\right) \\ \cos \left(\omega_{i} t+4 \pi / 3\right)\end{array}\right]$

To obtain a maximum voltage transfer ratio is added common-mode voltages to the target outputs voltages as shown in Eq. (6).

$\left[\mathrm{v}_{\mathrm{o}}(\mathrm{t})\right]=\left[\begin{array}{c}\mathrm{V}_{\mathrm{aN}}(\mathrm{t}) \\ \mathrm{V}_{\mathrm{bN}}(\mathrm{t}) \\ \mathrm{V}_{\mathrm{cN}}(\mathrm{t})\end{array}\right]=\mathrm{qV_{ \textrm {im } }}\left[\begin{array}{l}\cos \left(\omega_{\mathrm{o}} \mathrm{t}\right)-(1 / 6) \cos \left(3 \omega_{\mathrm{o}} \mathrm{t}\right)+(1 / 2 \sqrt{3}) \cos \left(3 \omega_{\mathrm{i}} \mathrm{t}\right) \\ \cos \left(\omega_{\mathrm{o}} \mathrm{t}+2 \pi / 3\right)-(1 / 6) \cos \left(3 \omega_{\mathrm{o}} \mathrm{t}\right)+(1 / 2 \sqrt{3}) \cos \left(3 \omega_{\mathrm{i}} \mathrm{t}\right) \\ \cos \left(\omega_{\mathrm{o}} \mathrm{t}+4 \pi / 3\right)-(1 / 6) \cos \left(3 \omega_{\mathrm{o}} \mathrm{t}\right)+(1 / 2 \sqrt{3}) \cos \left(3 \omega_{\mathrm{i}} \mathrm{t}\right)\end{array}\right]$

Where, $\mathrm{q}$ is the voltage gain. The common-mode voltages have no effect on the output line-to-line voltages, but allow the target outputs to fit within the input voltage envelope with a value of q up to $86,6 \%$ as illustrated in Fig. 2. It should be noted that a voltage ratio of $86,6 \%$ is the intrinsic maximum for any modulation method where the target output voltage equals the mean output voltage during each switching sequence. [6].

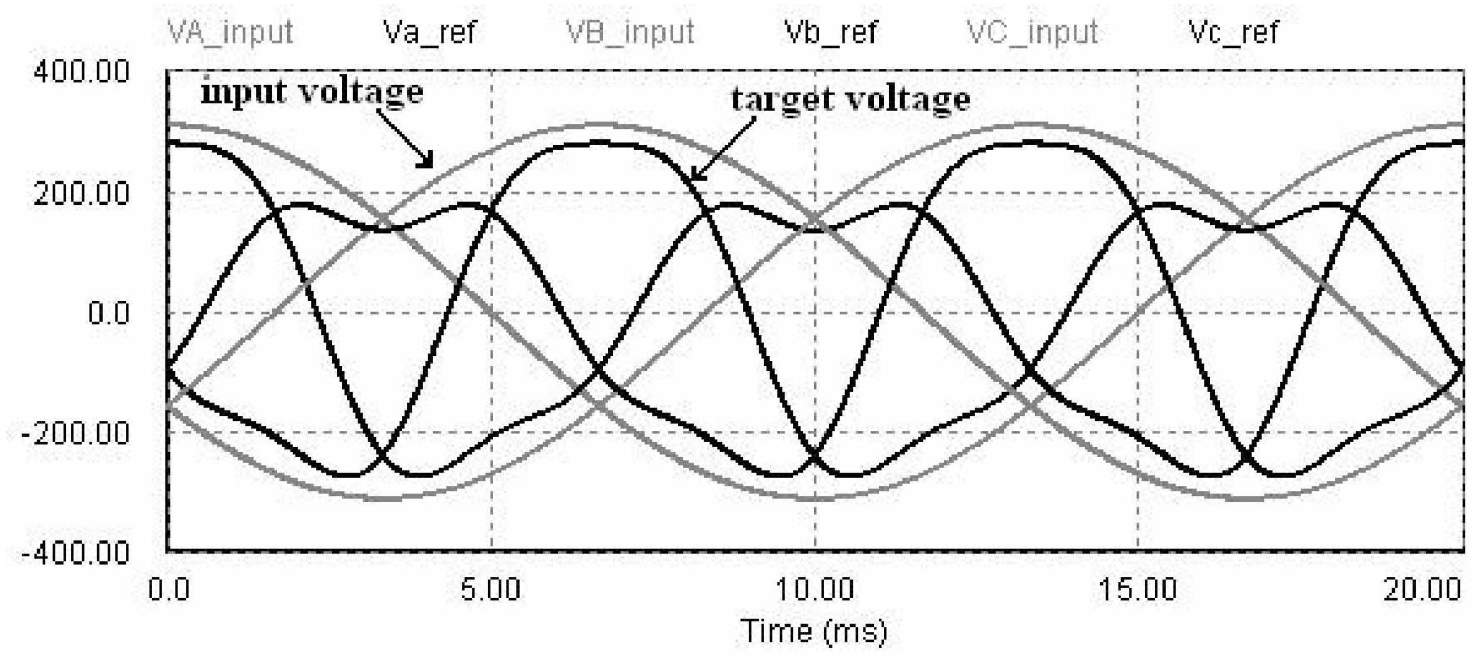

Figure (2): Input voltages and target voltages including common-mode voltages 
The formal statement of the algorithm, including displacement factor control, in Venturini's paper [7] is rather complex and appears unsuited for real time implementation. In fact, if unity input displacement factor is required, then the algorithm can be more simple in the form of eq. (7) [6].

$$
\mathrm{m}_{\mathrm{Kj}}=\frac{1}{3}\left[1+\frac{2 \mathrm{v}_{\mathrm{K}} \mathrm{v}_{\mathrm{j}}}{\mathrm{V}_{\mathrm{im}}^{2}}+\frac{2 \mathrm{q}}{3 \mathrm{q}_{\mathrm{m}}} \sin \left(\omega_{\mathrm{i}} \mathrm{t}+\beta_{\mathrm{K}}\right) \sin \left(3 \omega_{\mathrm{i}} \mathrm{t}\right)\right] \quad \mathrm{K}=\{\mathrm{A}, \mathrm{B}, \mathrm{C}\}, \mathrm{j}=\{\mathrm{a}, \mathrm{b}, \mathrm{c}\}, \beta_{\mathrm{K}}=0, \frac{2 \pi}{3}, \frac{4 \pi}{3}
$$

In the modeled system, firstly, the power circuit, including nine bidirectional-switches was designed. Then, an input filter and a clamp circuit were modeled to smooth distortion of the input current and to prevent damaging of the power switches due to over-voltages or over-currents possibly occurring during commutation, respectively. Then, duty cycles of bidirectional switches were calculated according to (8) using mathematical function block in PSIM.

$$
\mathrm{t}_{\mathrm{Kj}}=\mathrm{T}_{\mathrm{s}}\left[\frac{1}{3}+\frac{2 \mathrm{v}_{\mathrm{K}} \mathrm{v}_{\mathrm{j}}}{3 \mathrm{~V}_{\mathrm{im}}^{2}}+\frac{2 \mathrm{q}}{9 \mathrm{q}_{\mathrm{m}}} \sin \left(\omega_{\mathrm{i}} \mathrm{t}+\beta_{\mathrm{K}}\right) \sin \left(3 \omega_{\mathrm{i}} \mathrm{t}\right)\right] \quad \mathrm{K}=\{\mathrm{A}, \mathrm{B}, \mathrm{C}\}, \mathrm{j}=\{\mathrm{a}, \mathrm{b}, \mathrm{c}\}, \quad \beta_{\mathrm{K}}=0, \frac{2 \pi}{3}, \frac{4 \pi}{3}
$$

The switching functions $\left(\mathrm{S}_{\mathrm{Kj}}(\mathrm{t})\right)$, determining turn-on-time of the switches were obtained according to the logic statements in equation (9) by using duty cycles. These functions are gate-drive signals of the power switches. It is clearly given in Fig. 3, how only three switching functions $\left(\mathrm{S}_{\mathrm{Aa}}, \mathrm{S}_{\mathrm{Ba}}, \mathrm{S}_{\mathrm{Ca}}\right)$ are produced. The other switching functions can also be obtained alike simply [5].

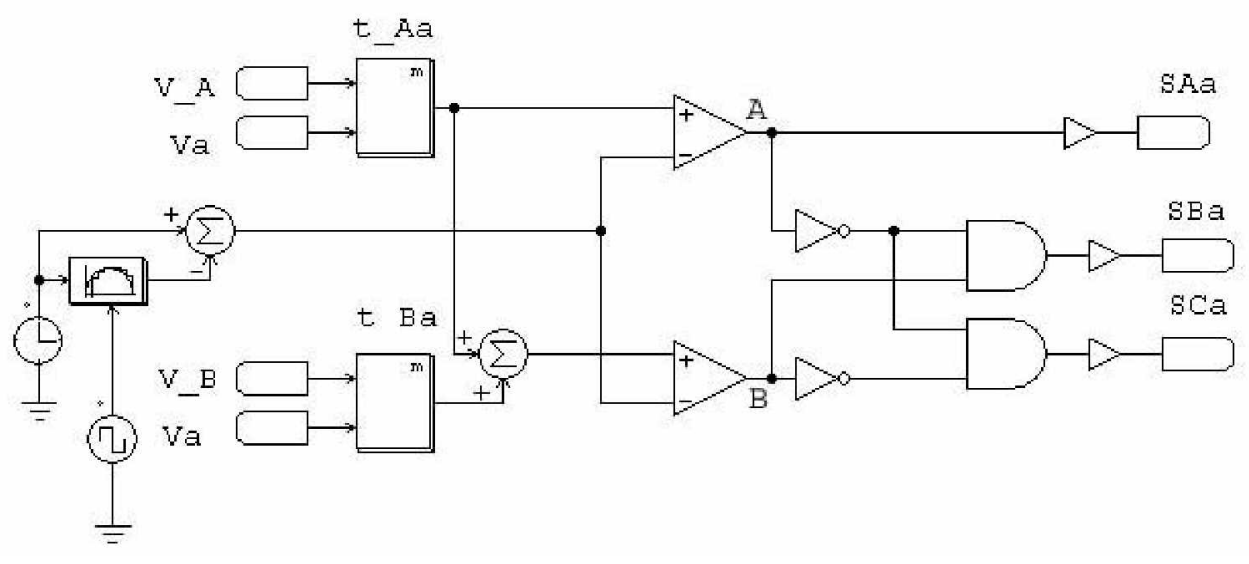

Figure (3): PSIM model developed to produce switching signals 
$\mathrm{S}_{\mathrm{Aj}}=(\mathrm{X})$

$\mathrm{S}_{\mathrm{Bj}}=\operatorname{not}(\mathrm{X})$ and $(\mathrm{Y}) \quad \mathrm{j}=\{\mathrm{a}, \mathrm{b}, \mathrm{c}\}$

$\mathrm{S}_{\mathrm{Cj}}=\operatorname{not}(\mathrm{X})$ and $\operatorname{not}(\mathrm{Y})$

\section{Results:}

Some simulation studies have been done using the following parameters: source voltage amplitude $V_{i}=311 \mathrm{~V}$, input frequency $f_{i}=50 \mathrm{~Hz}$, load resistance $\mathrm{R}=10 \Omega$, load inductance $\mathrm{L}=30 \mathrm{mH}$. The parameters of the input filter are $\mathrm{L}_{\mathrm{f}}=3 \mathrm{mH}, \mathrm{R}_{\mathrm{f}}=0.1 \Omega$ and $\mathrm{C}_{\mathrm{f}}=25 \mu \mathrm{F}$. Voltage gain $\mathrm{q}=0.8$, switching frequency $\mathrm{f}_{\mathrm{s}}=2 \mathrm{kHz}$ and simulation step $=$ $10 \mu \mathrm{s}$.

In the simulated system, the output voltages at the following parameters have been obtained: $\mathrm{f}_{\mathrm{o}}=25 \mathrm{~Hz}, 50 \mathrm{~Hz}, 100 \mathrm{~Hz}$ for $\mathrm{q}=0.8$. As a result, waveforms of output line voltages, output phase voltage with respect to neutral of source, output phase voltage with respect to neutral of load, output currents, filtered and unfiltered input currents are given.

In this paper, the waveforms of 25,50 and $100 \mathrm{~Hz}$-output frequency for 0.8 -voltage gain, $50 \mathrm{~Hz}$-input frequency and $2 \mathrm{kHz}$-switching frequency have been given. It is given the various waveforms for $25 \mathrm{~Hz}$-output frequency in Figure 4, $50 \mathrm{~Hz}$-output frequency in Figure 5 and $100 \mathrm{~Hz}$-output frequency in Figure 6.

Figure 4(a), 5(a) and 6(a) show the output line voltage of phase A. The mean of this pulsed waveform is sinusoidal, and the amplitude of the voltage equals to $80 \%$ of input line voltage for $\mathrm{q}=0,8$.

The output phase voltages with respect to neutral of source are given in Figure 4(b), 5(b) and 6(b). As illustrated in Figure 4(b), 5(b) and 6(b), frequency of output voltage is $25 \mathrm{~Hz}, 50 \mathrm{~Hz}$ and $100 \mathrm{~Hz}$, respectively.

Figure 4(c), 5(c) and 6(c) show the output line currents and output phase voltages with respect to neutral of load. As shown in these waveforms, the low-pass characteristic of the load produces an almost sinusoidal current.

Figure 4(d), 5(d) and 6(d) show that the input current generated by the MC has the form of several pulses with a high di/dt, making it necessary to introduce an input filter to avoid the generation of over-voltages.

Figures of 4(e), 5(e), and 6(e) show that the source current is free of high frequency harmonics, due to the effect of the input filter and, although the current in the output of the converter is lag from the output voltage, the input line current drawn from the source is in the same phase with the source phase voltage. 


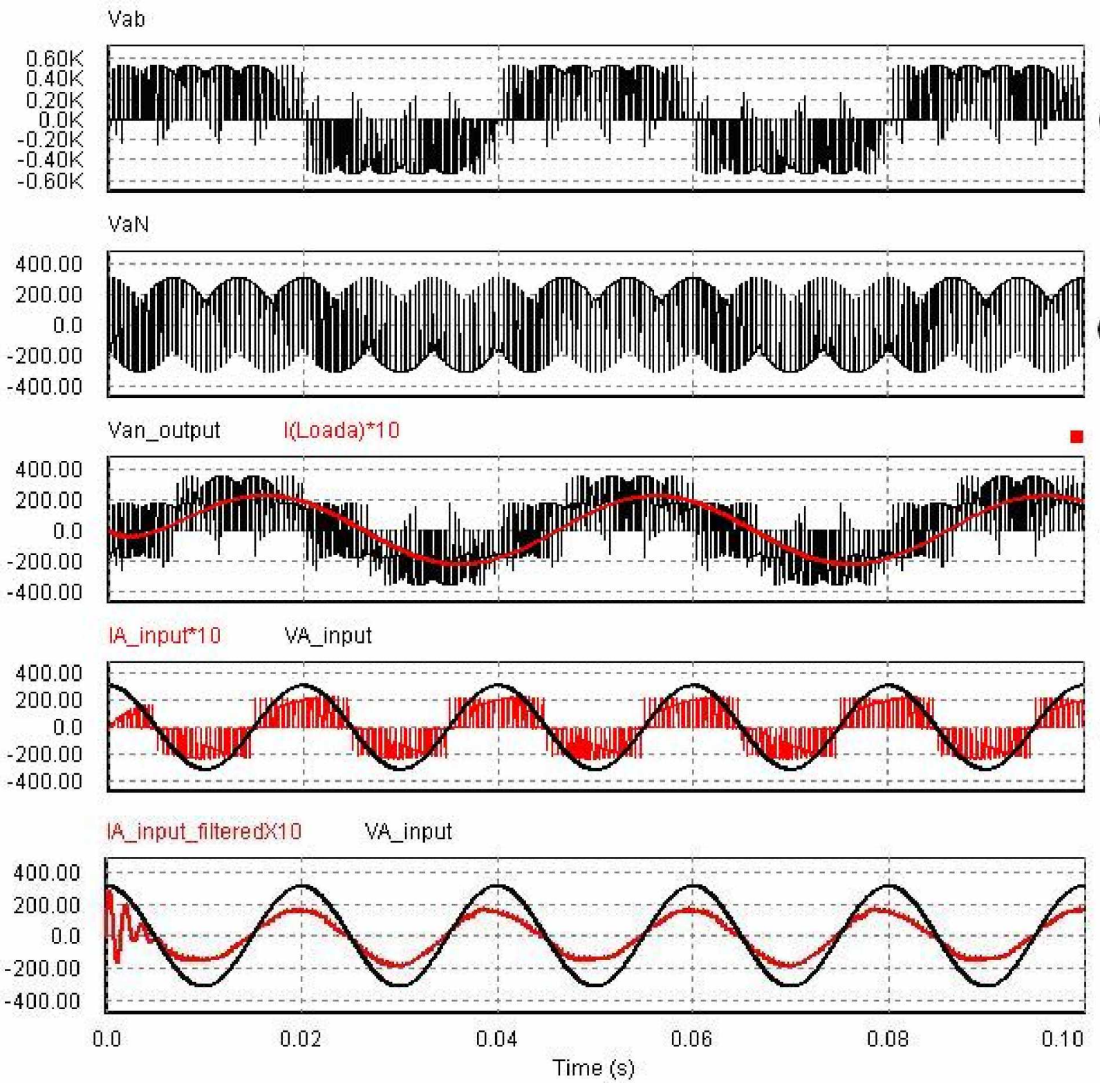

Figure (4): Simulation results for $f_{i}=50 \mathrm{~Hz}, f_{o}=25 \mathrm{~Hz}, f_{s}=2 \mathrm{kHz}$ and $q=0.8$

(a) Output line voltage $\left(V_{a b}\right)$,

(b) Output phase voltage with respect to neutral of source $\left(V_{a N}\right)$

(c) Output phase voltage and output current $\left(I_{a} \times 10\right)$

(d) Input phase voltage $\left(V_{S A}\right)$ and input current before the filter $\left(I_{A} \times 10\right)$

(e) Input phase voltage $\left(V_{S A}\right)$ and filtered input current $\left(I_{S A} \times 10\right)$ 


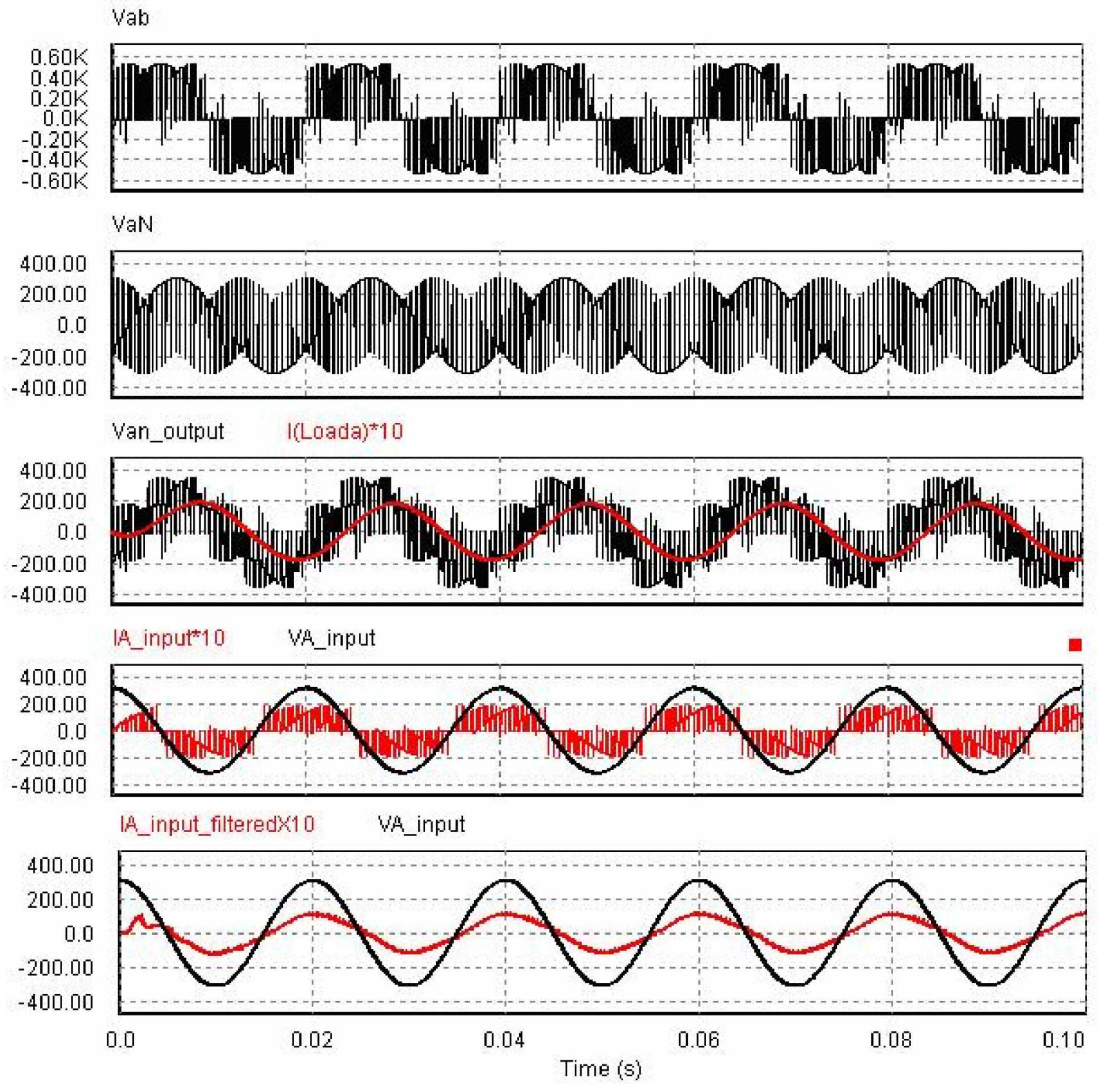

Figure (5): Simulation results for $f_{i}=50 \mathrm{~Hz}, f_{o}=50 \mathrm{~Hz}, f_{s}=2 \mathrm{kHz}$ and $q=0.8$

(a) Output line voltage $\left(V_{a b}\right)$,

(b) Output phase voltage with respect to neutral of source $\left(V_{a N}\right)$

(c) Output phase voltage and output current $\left(I_{a} \times 10\right)$

(d) Input phase voltage $\left(V_{s A}\right)$ and input current before the filter $\left(I_{A} x 10\right)$

(e) Input phase voltage $\left(V_{s A}\right)$ and filtered input current $\left(I_{S A} \times 10\right)$ 


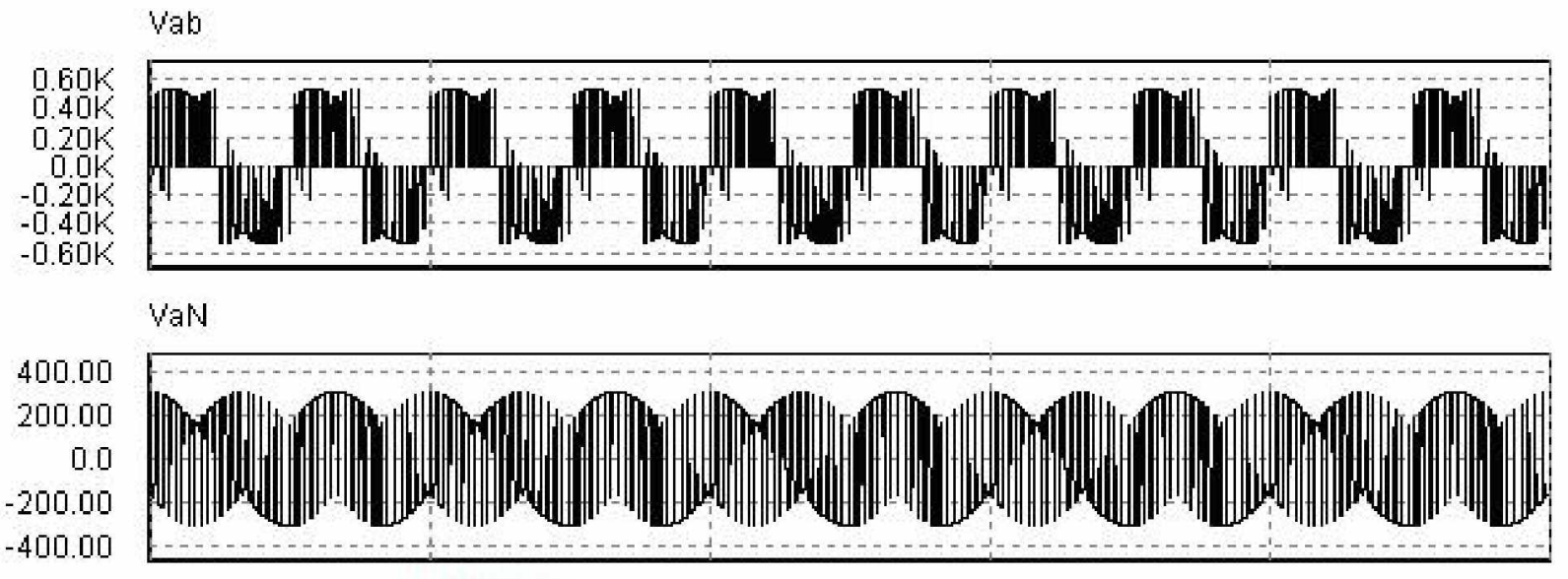

Van_output l(Loada) 20
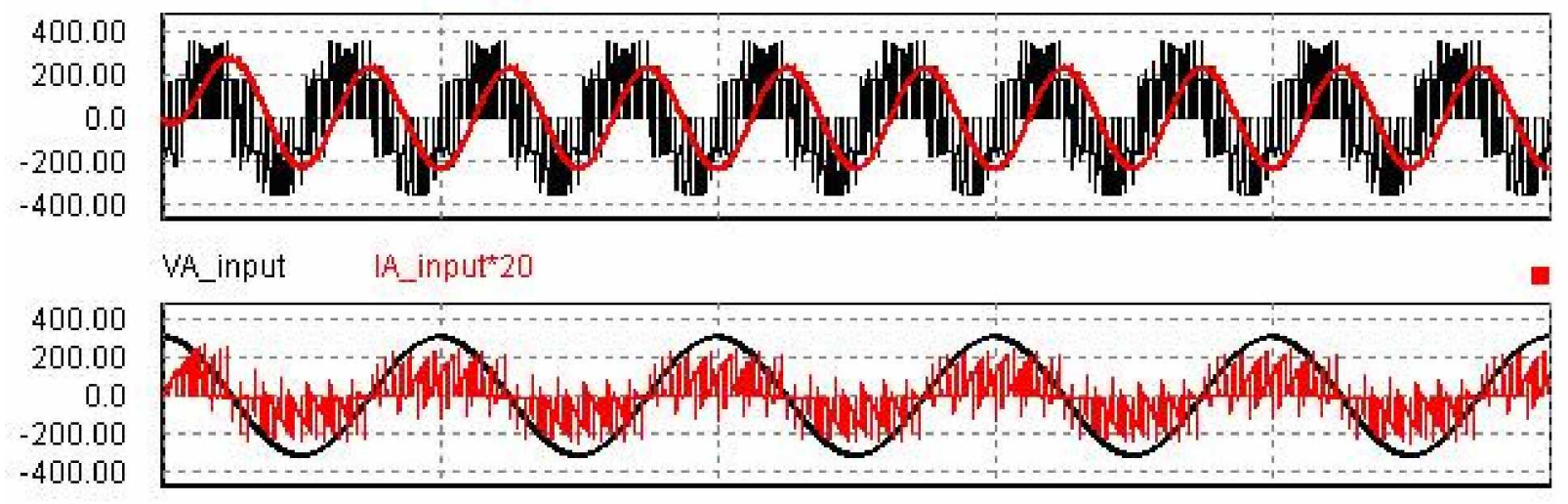

$$
-400.00
$$

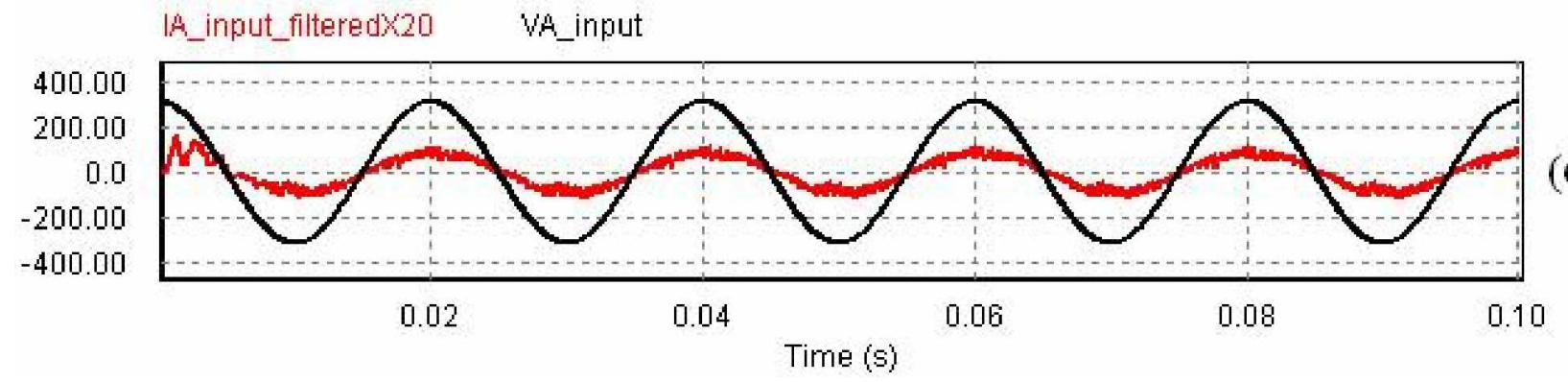

Figure (6): Simulation results for $f_{i}=50 \mathrm{~Hz}, f_{o}=100 \mathrm{~Hz}, f_{s}=2 \mathrm{kHz}$ and $q=0.8$

(a) Output line voltage $\left(V_{a b}\right)$,

(b) Output phase voltage with respect to neutral of source $\left(V_{a N}\right)$

(c) Output phase voltage and output current $\left(I_{a} \times 20\right)$

(d) Input phase voltage $\left(V_{s A}\right)$ and input current before the filter $\left(I_{A} \times 20\right)$

(e) Input phase voltage $\left(V_{S A}\right)$ and filtered input current $\left(I_{S A} \times 20\right)$ 


\section{Conclusions:}

The working principle and analysis of the MC that connects direct three-phase source to three-phase load and controlled with the optimum amplitude-DTFA has been presented. Modulation strategies and fundamental mathematical equations of the MC have been presented clearly. Also, modeling and simulation of the optimum amplitude-DTFA, which can give an output voltage with maximum amplitude has been implemented. The designed model has satisfactorily given the behavior of the MC including the impact of the input filter. The simulation results show that the modulation algorithm provides a unity input displacement factor even when the load has an inductive characteristic. As a result, the PSIM model presented can be confidently used in the construction stage of the matrix converter.

\section{Acknowledgment:}

- This study was supported by Scientific Research Project Found of Selcuk University (project number: 08701068).

, The authors gratefully acknowledge the support and delivered free license for their work by POWERSYS (www.powersys.fr) as the distributor of PSIM in Europe.

\section{References:}

[1] M. Venturini, A New Sine Wave in Sine Wave out, Conversion Technique Which Eliminates Reactive Elements, Proceedings of Powercon 7, pp. E3/1-E3/15, 1980.

[2] M. Venturini, A. Alesina, The Generalized Transformer: A New Bidirectional Sinusoidal Waveform Frequency Converter with Continuously Adjustable Input Power Factor, IEEE PESC'80, pp.242-252, 1980.

[3] D. Casadei, G. Serra, A. Tani, L. Zarri, Matrix Converter Modulation Strategies : A New General Approach Based on Space-Vector Representation of the Switch State, IEEE Transaction on Industrial Electronics, Vol. 49, pp. 370-381, 2002.

[4] Y. Tatar, S. Sünter, Pspice Modeling and Simulation of a Matrix Converter-Fed Induction Motor Drive, Electrical Engineering, Springer-Verlag, pp. 295-301, 2002.

[5] J. Rodriguez, E. Silva, F. Blaabjerk, et al., Matrix Converter Controlled with The Direct Transfer Function Approach: Analysis, Modelling and Simulation, International Journal of Electronics, Taylor \& Francis, Vol.92, pp.63-85, 2005. 
[6] P.W. Wheeler, J. Rodriguez, J.C. Clare, et al., Matrix Converters: a Technology Review, IEEE Transaction on Industrial Electronics, Vol. 49, no.2, pp.276-288, 2002.

[7] A. Alesina, M. Venturini, Analysis and Design of Optimum-Amplitude Nine Switch Direct AC-AC Converters, IEEE Transaction on Power Electronics, Vol. 4, No.1, pp. 101-112, January 1989.

\section{Nomenclatures:}

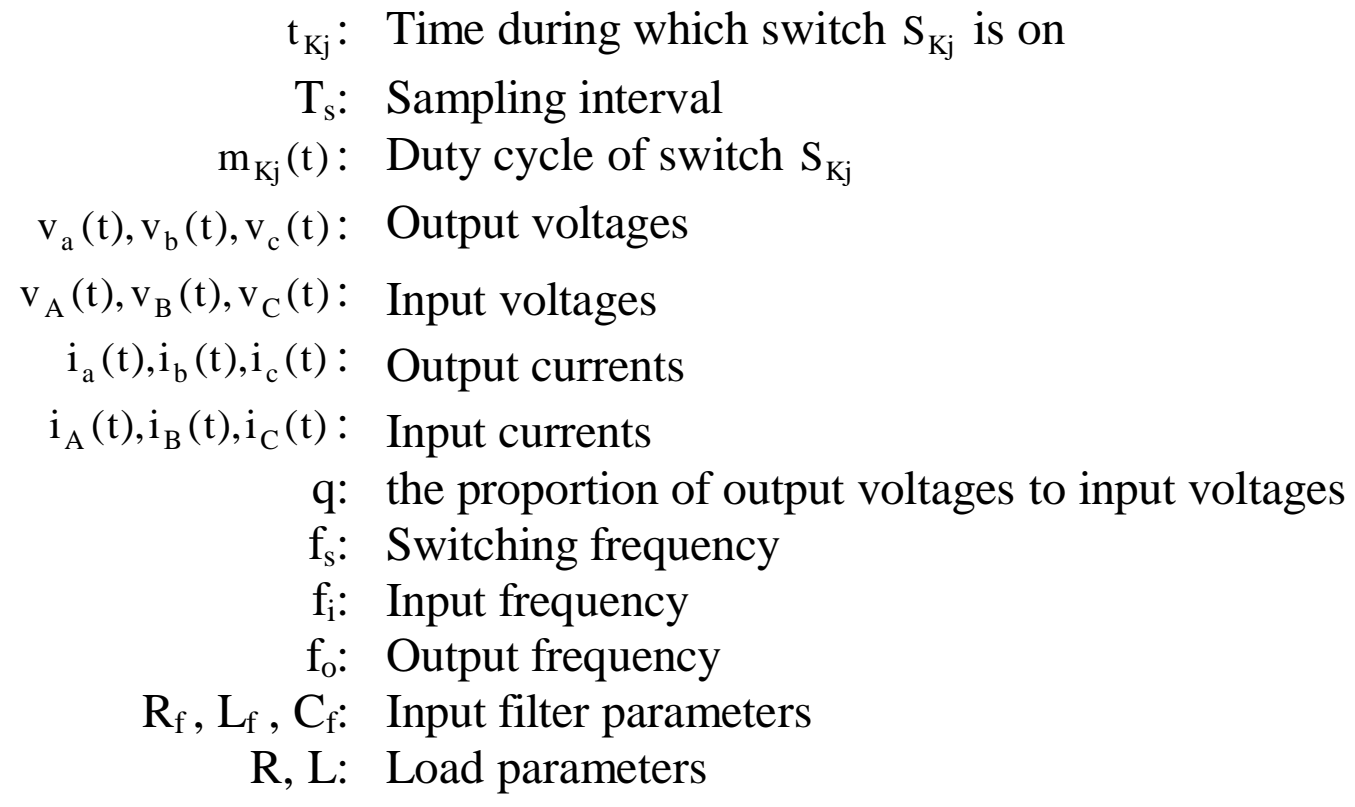

$t_{\mathrm{Kj}}$ : Time during which switch $\mathrm{S}_{\mathrm{Kj}}$ is on

$\mathrm{T}_{\mathrm{s}}$ : Sampling interval

$\mathrm{m}_{\mathrm{Kj}}(\mathrm{t})$ : Duty cycle of switch $\mathrm{S}_{\mathrm{Kj}}$

$\mathrm{v}_{\mathrm{a}}(\mathrm{t}), \mathrm{v}_{\mathrm{b}}(\mathrm{t}), \mathrm{v}_{\mathrm{c}}(\mathrm{t})$ : Output voltages

$\mathrm{v}_{\mathrm{A}}(\mathrm{t}), \mathrm{v}_{\mathrm{B}}(\mathrm{t}), \mathrm{v}_{\mathrm{C}}(\mathrm{t})$ : Input voltages

$\mathrm{i}_{\mathrm{a}}(\mathrm{t}), \mathrm{i}_{\mathrm{b}}(\mathrm{t}), \mathrm{i}_{\mathrm{c}}(\mathrm{t})$ : Output currents

$\mathrm{i}_{\mathrm{A}}(\mathrm{t}), \mathrm{i}_{\mathrm{B}}(\mathrm{t}), \mathrm{i}_{\mathrm{C}}(\mathrm{t})$ : Input currents

q: the proportion of output voltages to input voltages

$\mathrm{f}_{\mathrm{s}}$ : Switching frequency

$\mathrm{f}_{\mathrm{i}}$ : Input frequency

$\mathrm{f}_{\mathrm{o}}$ : Output frequency

$\mathrm{R}_{\mathrm{f}}, \mathrm{L}_{\mathrm{f}}, \mathrm{C}_{\mathrm{f}}$ : Input filter parameters

$\mathrm{R}, \mathrm{L}$ : Load parameters 